\title{
Cell-cycle-regulated phosphorylation of DNA replication factor $A$ from human and yeast cells
}

\author{
Salah-ud-Din, Steven J. Brill, Micaela P. Fairman, ${ }^{1}$ and Bruce Stillman \\ Cold Spring Harbor Laboratory, Cold Spring Harbor, New York 11724 USA
}

\begin{abstract}
Replication factor A (RF-A) is a multisubunit, cellular protein that functions with SV40 $T$ antigen during the initiation stage of DNA replication at the SV40 origin. It also cooperates with other replication factors to stimulate the activity of both polymerases $\alpha$ and $\delta$ during chain elongation. RF-A from both human and yeast cells is phosphorylated in a cell-cycle-dependent manner; the protein is phosphorylated at the $G_{1}-$ to $S$ phase transition, and dephosphorylation occurs at mitosis, thereby resetting this cycle. This observation provides a direct link between a protein required for DNA replication and cell-cycle-regulated protein phosphorylation.
\end{abstract}

[Key Words: DNA replication; cell cycle; DNA-binding protein]

Received February 16, 1990; revised version accepted March 26, 1990.

DNA replication is a precisely regulated event that is one of the ultimate targets for regulatory pathways that control cell proliferation and cell cycle progression. Controls are exerted in nonproliferating cells to ensure that the DNA does not replicate, whereas in proliferating cells, controls ensure that DNA replication occurs only once in the S phase of the cell cycle and that it is temporally linked to other cell division processes (Laskey et al. 1989). Essential replication proteins are not present in cells in the $\mathrm{G}_{0}$ state, and, consequently, DNA replication does not occur. During the $G_{0}$ to $G_{1}$ transition, however, a cascade of signal transduction events results in the synthesis of new replication proteins (Pardee 1989). In contrast, in proliferating cells, the proteins involved directly in DNA replication that have been examined heretofore are present at all stages of the cell cycle (Roberts and D'Urso 1988; Wahl et al. 1988; Wold et al. 1988; Cross et al. 1989; Morris and Mathews 1989). The $G_{1}-$ to S-phase transition therefore is regulated at a level other than en masse synthesis of all DNA replication factors.

In principle, the onset of DNA replication at the $G_{1}-$ to S-phase transition may be controlled by the synthesis of a subset of the replication machinery, by the post-translational activation of one or more preexisting replication factors, or by a change in their intracellular locale. Cell fusion experiments in the early 1970 s by Rao and Johnson provided evidence that the onset of DNA replication is affected by positive factors that accumulate

'Present address: Department of Zoology, University of Cambridge, Cambridge, CB2 3EJ, UK. only during $G_{1}$ and function only during the $S$ phase of the cell cycle (Rao and Johnson 1970; Rao et al. 1977; Cross et al. 1989|; however, the nature of these positive factors and their targets has remained elusive. One approach in identifying these important regulatory factors is first to understand the mechanism of DNA replication in eukaryotic cells and identify the replication proteins that may be regulated. In turn, these proteins can be used as substrates to identify the regulators. To this end, we have been studying DNA replication from the SV40 origin using a cell-free replication system.

The in vitro replication of SV40 DNA has proved to be an invaluable experimental system in understanding the mechanism of eukaryotic cell DNA replication and identifying cellular replication proteins /Challberg and Kelly 1989; Stillman 1989). Cell-free extracts prepared from monkey or human cells support the initiation and complete replication of plasmid DNAs containing the SV40 origin of DNA replication, provided that purified SV40 large-T antigen is provided from an exogenous source ( $\mathrm{Li}$ and Kelly 1984, 1985; Stillman and Gluzman 1985; Wobbe et al. 1985). To date, several cellular proteins have been identified as essential components of the cell-free replication system. These include replication factor A (RF-A; alternatively called RP-A or HeLa cell SSB), the proliferating cell nuclear antigen (PCNA), replication factor $C$ (RF-C), DNA polymerase $\alpha-$ DNA primase complex, DNA polymerase $\delta$, and DNA topoisomerases I and II (Murakami et al. 1986; Prelich et al. 1987; Wobbe et al. 1987; Yang et al. 1987; Fairman and Stillman 1988; Wold and Kelly 1988; Tsurimoto and Stillman 1989a; Wold et al. 1989). Another protein, phosphatase $2 \mathrm{~A}$, has been shown to stimulate SV40 
DNA replication in vitro, but it is not essential /Virshup and Kelly 1989; Virshup et al. 1989).

One of these factors, a multisubunit protein called RF-A, is of particular interest because it functions during the initiation and elongation stages of DNA replication and, consequently, may play a key regulatory role. The protein is found in the yeast Saccharomyces cerevisiae; therefore, the activity is highly conserved (Brill and Stillman 1989). RF-A functions as an auxiliary protein for both DNA polymerases $\alpha$ and $\delta$ and thus functions in the elongation stage of DNA replication (Kenny et al. 1989; Tsurimoto and Stillman 1989b); however, it also plays a key role during initiation. Multiple stages of initiation of DNA replication from the SV40 origin have been described. These include the recognition of the origin of DNA replication by SV40 T antigen, the formation of oligomeric structures of $\mathrm{T}$ antigen that locally unwind the replication origin, and the subsequent participation of RF-A in promoting extensive unwinding of the origin DNA (Dean et al. 1987; Wold and Kelly 1987; Boroweic and Hurwitz 1988; Mastrangelo et al. 1989; Roberts 1989; Tsurimoto et al. 1989). The unwinding of the origin of replication by $T$ antigen and cellular proteins has been shown to be affected by the cell cycle stage from which the cell extracts were isolated, $G_{1}$ extracts had a lower specific unwinding activity than extracts prepared from cells in the $S$ or $G_{2}$ phases (Roberts and $D^{\prime}$ Urso 1988). Variations in the amount of RF-A could not account for these results, raising the possibility that RF-A activity may be regulated post-translationally. Therefore, we have examined whether RF-A was subject to cell-cycle regulation in both human and yeast cells.

\section{Results}

$h R F-A$ is overproduced in transformed and tumor cells

RF-A was purified from human 293 cells (henceforth called hRF-A) as a multisubunit protein containing polypeptides with relative masses of $70,000,34,000$, and 11,000 daltons $(p 70, p 34$, and $\mathrm{p} 11$, respectively) that are tightly complexed together (Fairman and Stillman 1988; Wold and Kelly 1988). The purified protein was injected into a rabbit, and a polyclonal antiserum was obtained that recognized all three subunits by immunoprecipitation from an SDS-denatured, ${ }^{35}$ S-labeled extract of 293 cells (Fig. 1A, lane 4) or by immunoblot analysis (Fig. 1B, lane 4). A preimmune serum did not detect hRF-A subunits by these procedures (Fig. 1A,B, lanes 5 ). In addition, purified hRF-A was injected into mice, and a panel of monoclonal antibodies was obtained that recognized the p70 and p34 subunits (S. Din and B. Stillman, in prep.). Two of these monoclonal antibodies, p70-9 and p34-20, were selected because they specifically recognized the p70 and p34 subunits of hRF-A, respectively, by use of immunoprecipitation and immunoblotting techniques (Fig. 1A,B, lanes 1 and 2). A control monoclonal antibody, directed against SV40 $\mathrm{T}$ antigen (pAb419), did not recognize any cellular proteins (Fig. 1A,B, lanes 3). Both p70-9 and p34-20 inhibited SV40
DNA replication in vitro and immunoprecipitated the hRF-A complex (i.e., p70, p34, and p11) from ${ }^{35}$ S-labeled extracts that had not been denatured (see Fig. 2; S. Din and B. Stillman, in prep.) Therefore, these monoclonal and polyclonal antibodies are specific for hRF-A.

SV40 DNA replicates in permissive monkey cells and semipermissive human cells. Cell-free extracts prepared from cells from both species support efficient DNA replication in the presence of added SV40 T antigen. The 293 cell line an adenovirus-transformed embryonic kidney cell line) and the HeLa cell line produced more RF-A relative to total cell protein than did normal, nontransformed diploid fibroblasts (WI38 cell strain) (Fig. 1C). This was consistent in a number of experiments and was also true for PCNA (data not shown). Because DNA synthesis in these transformed and tumor cells is still restricted to a specific phase of the cell cycle, regulation of the onset of $S$ phase is unaffected by the amounts of these replication factors.

\section{Phosphorylation of hRF-A}

Immunoprecipitation of hRF-A revealed faint bands that migrated slightly slower than the predominant p34 subunit (Fig. 1A). The separation of these bands was dependent on the gel electrophoresis conditions, which were optimized for subsequent experiments by varying the running voltage and the ratio of acrylamide to bis-acrylamide. When hRF-A was immunoprecipitated from a ${ }^{35}$ S-labeled 293 cell extract under nondenaturing conditions and resolved in an SDS-polyacrylamide gel under optimal conditions, the p34 subunit appeared as a more pronounced series of bands (Fig. 2A, lane 1). The slower migrating forms were sensitive to digestion with alkaline phosphatase (Fig. 2A, lane 2), suggesting that they were due to phosphorylation of the $\mathrm{p} 34$ subunit. This was confirmed by labeling 293 cells with ${ }^{32} \mathrm{P}$ and immunoprecipitating hRF-A with the rabbit polyclonal antisera (Fig. 2B, lane 1). Only the p34 subunit was labeled under these conditions, however, in some experiments, phosphorylation of the p70 subunit was observed. The label was removed by digestion with alkaline phosphatase (Fig. 2B, lane 2). Acid hydrolysis of the ${ }^{32} \mathrm{P}$-labeled p34 protein revealed that phosphorylation occurred exclusively on serine residues (Fig. 2C).

\section{Cell-cycle-dependent phosphorylation of hRF-A}

Because hRF-A is involved in an early stage of DNA replication, it may be a target for the regulation of DNA replication. Therefore, we sought to determine whether the levels of hRF-A, or its phosphorylation state, varied throughout the cell cycle. To this end, a population of logarithmically growing HeLa cells was separated into the various stages of the cell cycle by centrifugal elutriation, which separates cells on the basis of cell size. Because cell growth is coupled to the cell cycle progression, this effectively separates cells into various stages of the cell cycle, as determined by their DNA content (Fig. 3A,B). Whole-cell lysates from each fraction were 


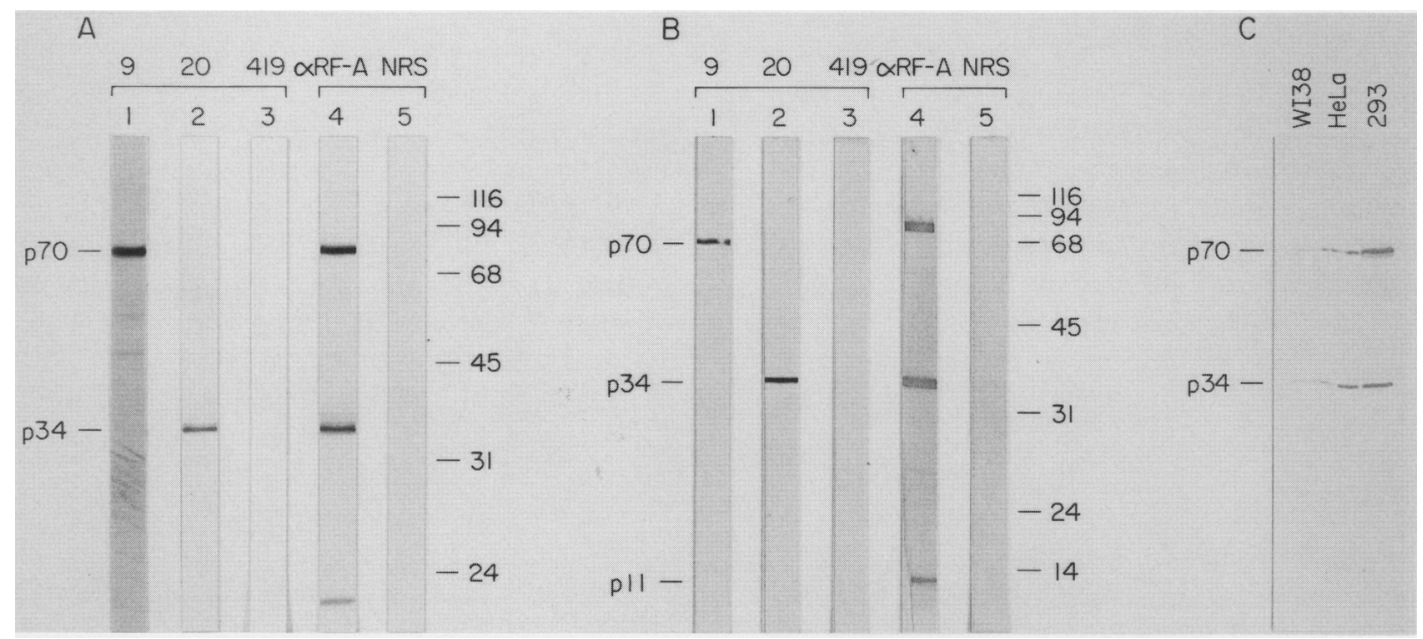

Figure 1. Immunological detection of human RF-A. (A) Immunoprecipitation of $\left[{ }^{35}\right.$ S]methionine-labeled 293 human cell lysate under denatured conditions with the following antibodies: (lane 1) p70-9; (lane 2) p34-20; (lane 3) antibody against SV40 T antigen, pAb419; (lane 4) polyclonal anti RF-A serum; (lane 5) normal rabbit serum. (B) Immunoblot analysis of human RF-A from 293 cells. Primary antibodies were p70-9 (lane 1); p34-20 (lane 2); pAb419 (lane 3); polyclonal anti RF-A serum (lane 4); normal rabbit serum (lane 5). (C) Immunoblot detection of RF-A with a combination of monoclonal antibodies p 70-9 and p34-20 in extracts from WI38, HeLa, and 293 human cells. In this blot, equal amounts of protein from each cell type were loaded onto the gel. The gels shown were $15 \%$ (in $A$ ) or $12 \%$ (in $B$ and $C$ ). Protein marker molecular masses are shown at right; the position of the p70 and p34 subunits are shown at left.

prepared, and the proteins were separated by SDS-PAGE and blotting to nitrocellulose filters. Probing one immunoblot with anti-hRF-A rabbit polyclonal antisera, which detected all three subunits, demonstrated that the amount of hRF-A did not vary throughout the cell cycle (Fig. 3C). The half-life of hRF-A in 293 cells is $>12 \mathrm{hr}$ (data not shown), consistent with the observation that the protein levels do not vary significantly during the cell cycle. But a faint upper $\mathrm{p} 34$ band was visible in extracts derived from the $\mathrm{S}$ - and $\mathrm{G}_{2}$-phase cells, suggesting that a fraction of the p34 subunit was phosphorylated at these stages. Similar immunoblots, using the p70-9 and p34-20 monoclonal antibodies (Fig. 3D,E), confirmed these observations, but indicated more clearly the phosphorylated forms of p34 in the $S$ and $G_{2}$ phases of the cell cycle and the apparent absence of the phosphorylated form in the $G_{1}$ phase.

A portion of the fractionated cells was placed back into culture and labeled with ${ }^{32} \mathrm{P}$ ] orthophosphate for 1.5 $\mathrm{hr}$. Cell lysates were prepared, and the p34 subunit was immunoprecipitated with the p34-20 monoclonal antibody (Fig. 3F). By labeling with ${ }^{32} \mathrm{P}$, phosphorylation of the $34 \mathrm{~K}$ subunit was observed slightly earlier in the cell cycle than the accumulation of the slow migrating form. This analysis revealed that phosphorylation of the p34 subunit did not occur in the $G_{1}$ phase but was restricted
Figure 2. Phosphorylation of hRF-A (p34 subunit). $|A|$ The ${ }^{35}$ S]methionine-labeled RF-A prepared from 293 cells by immunoprecipitation under native conditions with monoclonal antibody p34-20 was subjected to electrophoresis in an SDS $-15 \%$ polyacrylamide gel. Prior to electrophoresis, $20 \mu$ l of buffer [50 mM Tris ( $\mathrm{pH} 8.0$ ), $5 \mathrm{mM} \mathrm{MgCl}_{2}$, and 25 $\mathrm{mM} \mathrm{NaCl}]$ was added with $(+\mid$ or without $|-| 1$ unit of calf intestinal alkaline phosphatase (Boehringer-Mannheim) to the immunobeads, followed by incubation for $15 \mathrm{~min}$ at $37^{\circ} \mathrm{C}$. $(B)$ The $\left[{ }^{32} \mathrm{P}\right]$ orthophosphate-labeled RF-A prepared from 293 cells by immunoprecipitation under native conditions with polyclonal antibody against all three subunits of RF-A. Samples were treated with or without alkaline phosphatase, as in $A .(C)$ Two-dimensional phosphoamino acid analysis of ${ }^{32} \mathrm{P}$-labeled $\mathrm{p} 34$ subunit. The dotted shapes indicate the migration of unlabeled marker phosphoamino acids. Electrophoresis at $\mathrm{pH} 1.9$ in the first dimension was from right to left and at $\mathrm{pH} 3.5$ in the second dimension from bottom to top.

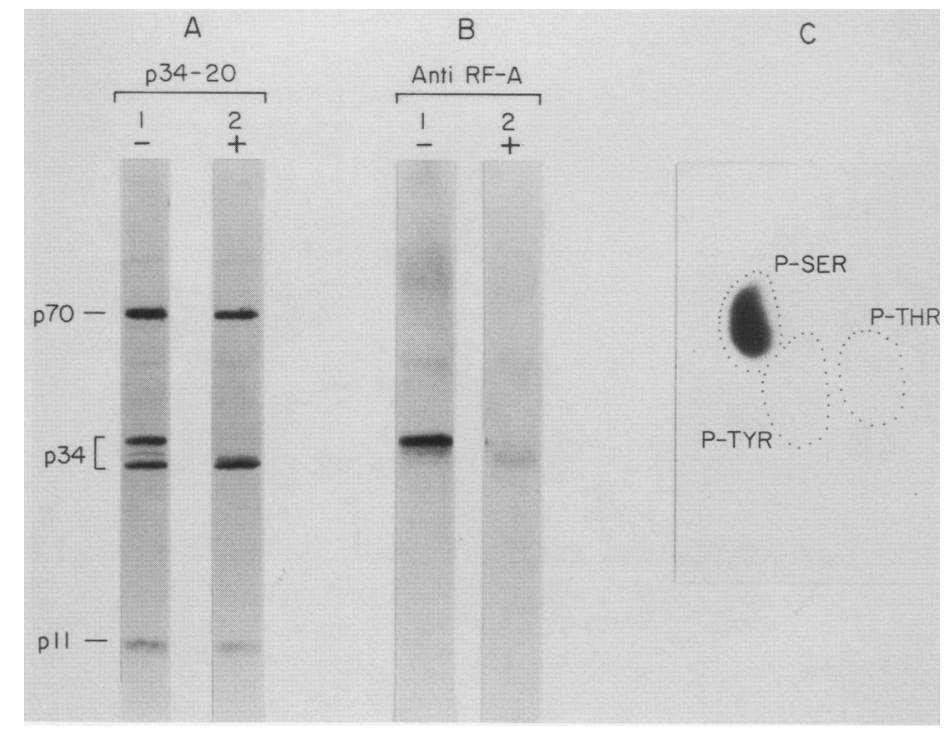


A

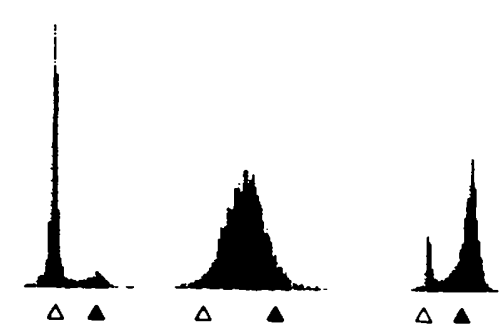

B
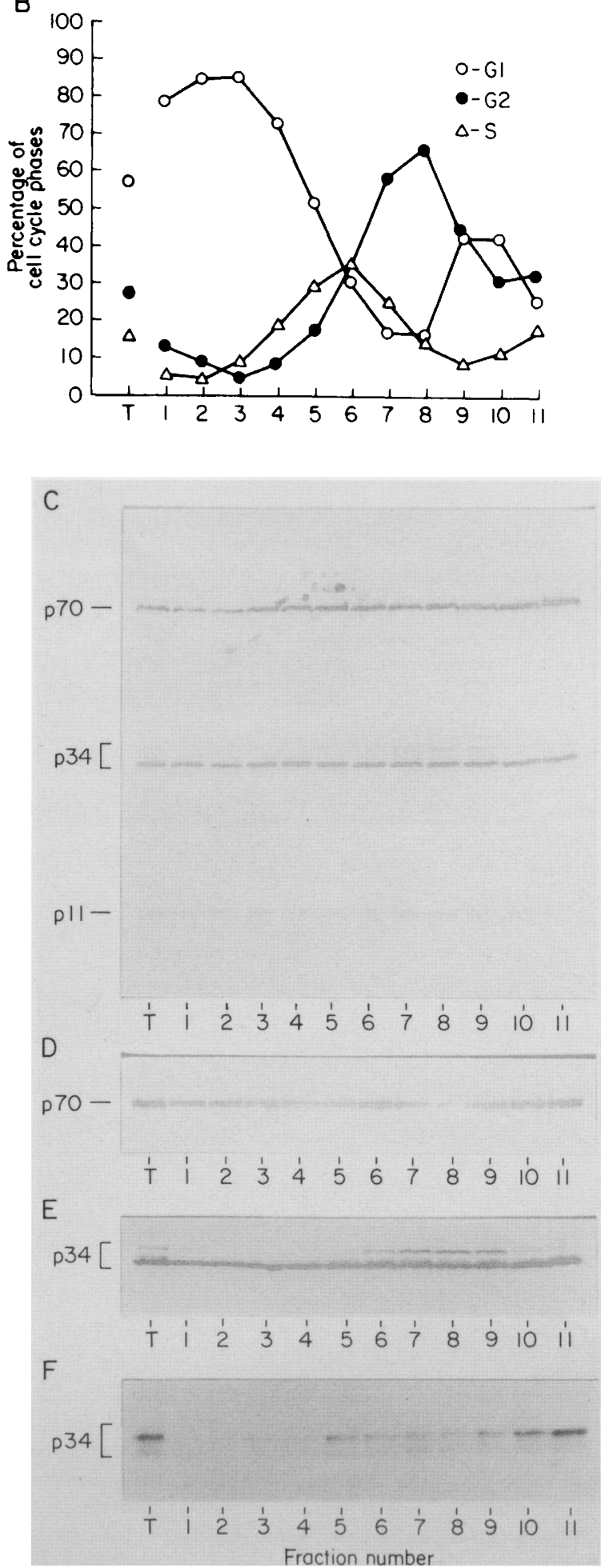

to the $S$ and $G_{2}$ phases and is consistent with accumulation of the phosphorylated protein detected by immunoblot techniques.

To determine whether the p34 subunit remained phosphorylated until the start of mitosis, HeLa cells grown on plastic were treated for $16 \mathrm{hr}$ with the microtubule-disrupting drug nocodazole. This procedure yielded a high percentage of cells arrested in mitosis (Fig. 4). Mitotic cells were separated from interphase cells by shaking off the mitotic cells, and lysates were prepared from both pools. An immunoblot with the p34-20 monoclonal antibody revealed that essentially all of the $34 \mathrm{~K}$ subunit of hRF-A was phosphorylated in the cells blocked in mitosis, whereas $\sim 40-50 \%$ of the protein was phosphorylated in interphase cells (Fig. 4). The fact that all of the p34 subunit was phosphorylated in cells blocked with nocodazole may be a result of the abnormally long time spent in mitosis.

These results demonstrate that the levels of the three subunits of hRF-A do not vary with cell-cycle progression; however, a fraction of the p34 subunit is phosphorylated in the $S$ and $G_{2}$ phases of the cell cycle, but not in the $G_{1}$ phase. Glycerol gradient sedimentation of extracts prepared from logarithmically growing cells demonstrated that some of the p34 subunit was not complexed with the p70 subunit and that this free p34 was not phosphorylated (i.e., there was an absence of the slow migrating forms). In contrast, the p34 subunit that was bound to the p70 subunit was present in both the phosphorylated and unphosphorylated forms / data not shown). Therefore, cell-cycle-dependent phosphorylation of the p34 subunit appears to be dependent on its association with the other subunits. Finally, dephosphorylation of the p34 subunit appears to occur late in mitosis, thereby resetting the phosphorylation cycle.

\section{Phosphorylation of RF-A is cell-cycle regulated in yeast}

Recently, we reported the identification of a homolog of hRF-A in the yeast Saccharomyces cerevisiae (Brill and Stillman 1989). The yeast homolog (yRF-A) is composed of three subunits with relative molecular masses of

Figure 3. Cell-cycle regulation of hRF-A. Logarithmically growing HeLa cells were fractionated by centrifugal elutriation, and the percentage of cells in various stages of the cell cycle was determined by DNA content. $|B|$ The percentage of cells in $G_{1}, S$, and $G_{2}$ for each elutriation fraction $(1-11)$, as well as the values for unfractionated cells $(T)$. $(A)$ Flow cytometric profiles of DNA content of cells from fractions 2,6 , and $8 .(\triangle) 2 N$ DNA content; ( $\Delta) 4 \mathrm{~N}$ DNA content. $(C-E)$ Extracts from $2 \times 10^{5}$ cells were prepared and subjected to SDS-12\% PAGE, and immunoblots were probed either with anti-hRF-A polyclonal antisera $(C)$, monoclonal antibody $\mathrm{p} 70-9(D)$, or monoclonal antibody p34-20 $(E) .(F) 5 \times 10^{6} \mathrm{HeLa}$ cells from each elutriated fraction were labeled with $2 \mathrm{mCi}$ of $\left[{ }^{32} \mathrm{P}\right]$ orthophosphate in $1 \mathrm{ml}$ of phosphate-free DMEM supplemented with $2 \%$ (vol/vol) dialyzed FBS for $1.5 \mathrm{hr}$ at $37^{\circ} \mathrm{C}$. Cell extracts were prepared, and hRF-A was immunoprecipitated with monoclonal antibody p34-20, separated by gel electrophoresis, and detected by autoradiography. The positions of the hRF-A subunits are indicated. 


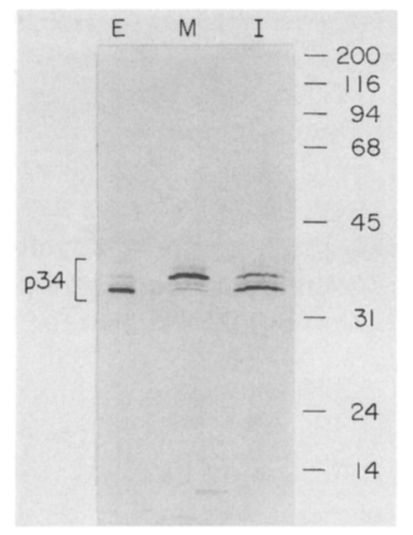

Figure 4. Immunoblot analysis of nocodazole-exposed HeLa cells probed with monoclonal p34-20. HeLa cells were exposed to $40 \mathrm{ng} / \mathrm{ml}$ of nocodazole for $16 \mathrm{hr}$, and mitotic arrested cells were shaken from the dishes and collected by centrifugation. The cells that remained attached to the dishes were scraped with a rubber policeman. The cells were lysed in sample buffer, and the protein concentration was determined by the method of Lowry et al. (1951). Protein $(30 \mu \mathrm{g})$ was loaded on each lane and resolved on a SDS- $12 \%$ polyacrylamide gel, transferred to nitrocellulose, and probed with monoclonal antibodies p34-20 and p70-9. (E) Exponentially growing cells (control); (M) mitotic arrested cells; (I) interphase cells.

$69,000,36,000$, and 13,000 daltons (p69, p36, and p13). Similar to the human protein, yRF-A was found to possess an alkaline phosphatase-sensitive modification on the intermediate subunit. Polyclonal antibodies were raised against the individual subunits of yRF-A by injection of SDS-PAGE-purified subunit protein into rabbits. Antibody raised against the p36 subunit specifically immunoprecipitated a $36-\mathrm{kD}$ phosphate-labeled protein from ${ }^{32} \mathrm{P}$-labeled cell extracts (Fig. 5, lane 2). The ${ }^{32} \mathrm{P}-\mathrm{la}-$ beled band comigrated with the upper band of a $36-\mathrm{kD}$ doublet immunoprecipitated from ${ }^{35}$ S-labeled cell extracts (Fig. 5, lane 4). Under the nondenaturing conditions used in this experiment, the antibody raised against the p36 subunit coprecipitated yRF-A subunits p69 and pl3 (Fig. 5, lane 4). The high-molecular-weight ${ }^{32} \mathrm{P}$-labeled band in lane 2 is possibly a phosphorylated form of the yRF-A p69 subunit.

We reasoned that the well-characterized yeast cell cycle should allow a precise examination of the regulation of phosphorylation of this protein. Indeed, immunoblot analysis of cells synchronized by the conventional technique of release from $\alpha$-factor arrest indicated that the p36 subunit of yRF-A was unphosphorylated in $G_{1}$ and became phosphorylated later in the cell cycle (data not shown). Under these conditions, however, we could not detect a return to the fully unphosphorylated condition following the end of the first cell cycle, most likely as a result of a loss of synchrony in the culture. Because growth arrest with $\alpha$-factor may have led to possible artifacts, yeast cells were subjected to centrifugal elutriation.

Small unbudded yeast cells, which correspond to cells in the $G_{1}$ phase, were isolated by centrifugal elutriation, placed back into culture, and allowed to progress synchronously through the cell cycle. The synchrony achieved by use of this method is shown in Figure 6A. Here, the proportion of unbudded single cells $\left(G_{1}\right.$ phase $)$, small budded cells (S phase), and large budded cells $\left\langle\mathrm{G}_{2} / \mathrm{M}\right.$ phase $)$ was determined by microscopic analysis of the culture during growth. Initially, the starting population of single cells $(80 \%)$ decreased, and the proportion of small budded cells increased. Later, the proportion of small budded cells decreased, and the proportion of large budded cells increased. It can be seen that a second cell cycle began in the $75-$ to $90-\mathrm{min}$ interval in agreement with the 90-min doubling time of this strain.

Aliquots of cells were taken from this culture at various times and analyzed by immunoblot for phosphorylation of the yRF-A p36 subunit. The initial population of $G_{1}$ cells gave rise to a single p36 band indicative of the unphosphorylated form (Fig. 6B). Shortly thereafter, at 15 and $30 \mathrm{~min}$, increasing amounts of the phosphorylated form of p36 appeared. As the second cycle commenced, yRF-A p36 did not return to a completely unphosphorylated form; the upper band persisted throughout the remainder of the experiment. We note, however, that the proportion of unbudded single cells never returned to the level seen at the start of the experiment (Fig. 6A). Therefore, it is reasonable to conclude that the protein is unphosphorylated in the $G_{1}$ phase of the cell cycle and that the persistence of the phosphorylated form was a result of a loss of synchrony in the culture.

The timing of phosphorylation correlated strongly with the appearance of small budded cells and, therefore,

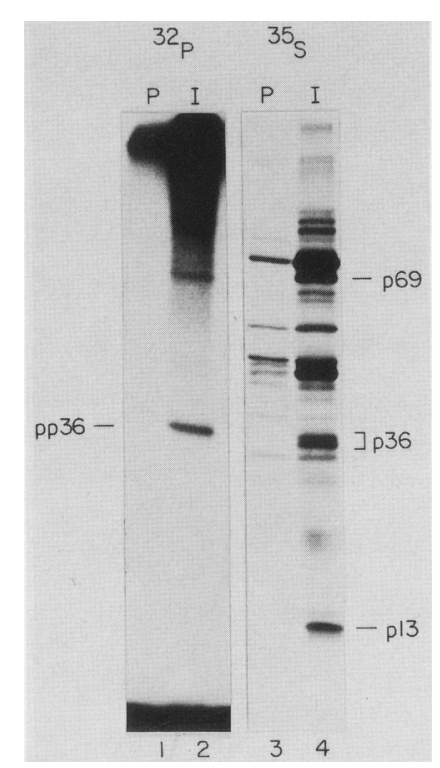

Figure 5. Native immunoprecipitation of yRF-A. Yeast cells, labeled with either [ ${ }^{32} \mathrm{P}$ ) orthophosphate (lanes 1 and 2) or ${ }^{35} \mathrm{~S}$ (lanes 3 and 4 ) were incubated with either preimmune $(\mathrm{P})$ or immune (I) sera prior to precipitation with protein A-Sepharose beads. The samples were subjected to electrophoresis on a $15 \%$ SDS-polyacrylamide gel. The positions of the yRF-A subunits are shown. 
A

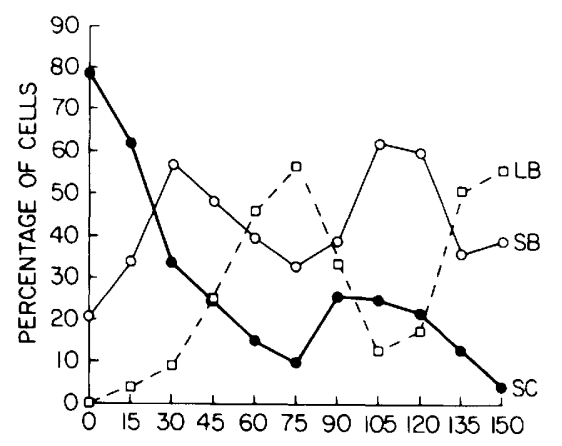

B

p36 [

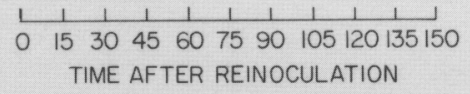

C

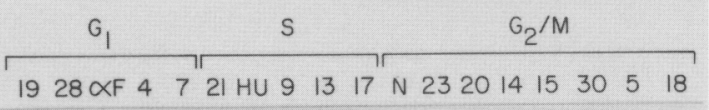

p36 [

Figure 6. Cell-cycle-regulated phosphorylation of yRF-A. $|A|$ Synchronization of yeast cells. Unbudded single cells were isolated by centrifugal elutriation and placed into culture. At various times, aliquots were fixed and microscopically examined for cell morphology. The percentage of unbudded single cells (SC), small budded cells (SB), and large budded cells (LB) is shown. (B) Immunoblot analysis of yRF-A p36 through the cell cycle. Extracts were prepared from the cells described in $A$, resolved on a SDS- $17 \%$ polyacrylamide gel, blotted to nitrocellulose, and probed with affinity-purified anti-p36 antibody. $|C|$ Immunoblot analysis of yRF-A p36 from cell-cycle-arrested cultures. Extracts of cdc strains arrested at $38^{\circ} \mathrm{C}$ for $5 \mathrm{hr}$, or wildtype cells treated with $\alpha$-factor $(\alpha \mathrm{F})$, hydroxyurea (HU), or nocodazole $(\mathrm{N})$ for $3.5 \mathrm{hr}$ were blotted and probed with affinity-purified anti-p36 antibody.

the onset of DNA synthesis. To determine more precisely the timing of yRF-A phosphorylation, cells were blocked at specific places in the cell cycle by use of a variety of chemicals and cell-division-cycle (cdc) mutations. The arrested cells were then analyzed for the level of yRF-A phosphorylation by immunoblot.
yRF-A from cells blocked in the $G_{1}$ phase of the cell cycle by cdc arrest or by treatment with $\alpha$-factor was found only in the unphosphorylated form (Fig. 6C). In contrast, cells arrested during $S$ phase by cdc mutations or by treatment with hydroxyurea contained yRF-A that was highly phosphorylated. Although there are no clear markers of the $G_{2}$ phase of the cell cycle in yeast, many mutations have been identified that block the cell cycle after the completion of DNA synthesis. In Figure 6C we refer to these mutations collectively as $\mathrm{G}_{2} / \mathrm{M}$-phase arrest points, noting that nocodazole, $c d c 23, c d c 20, c d c 14$, $c d c 15$, and $c d c 30$ arrest after medial nuclear division and prior to late nuclear division, whereas the arrest points of $c d c 5$ and $c d c 18$ have been placed after late nuclear division and prior to nuclear reorganization and cytokinesis (Pringle and Hartwell 1981). These conditions indicated that yRF-A from cells blocked after the completion of DNA synthesis was again the unphosphorylated form of yRF-A p36 (Fig. 6C).

Taken together, the data in Figure 6 suggest that yRF-A is phosphorylated specifically in $S$ phase. In all cases examined, phosphorylation was observed in cells blocked after DNA synthesis is initiated [e.g., cdc21 etc., and recently $c d c 2$ (data not shown)] but not in cells blocked prior to the start of DNA synthesis [e.g., $c d c 7$ etc., and recently $c d c 25$ (data not shown)]. Interestingly, the $C D C 7$ gene encodes a putative protein kinase (Patterson et al. 1986) whose activity is required extremely late in $G_{1}$ for the initiation of mitotic DNA synthesis (Hartwell 1973). The substrates for this kinase are unknown. It is intriguing that yRF-A is unphosphorylated in the absence of the CDC7 kinase, and it will be of interest to determine whether this kinase will phosphorylate yRF-A in vitro. When $c d c 7$-arrested cells were returned to the permissive temperature, phosphorylation of yRF-A was observed within 15-20 min (data not shown). This corresponds roughly to the time required to begin DNA replication (Reynolds et al. 1989).

Dephosphorylation of yRF-A appears to occur in either $G_{2}$ or $M$ phase. Because of the absence of clear $G_{2}$ arrest points, a distinction between the two phases is difficult to make. Furthermore, the experiment described in Figure $6 \mathrm{C}$ should be interpreted cautiously because it is known that although a particular cdc mutation may block one or more biochemical pathways, other pathways continue normally or change their sequence of steps in response to the blocked pathway. The conclusions based on Figure $6 \mathrm{C}$ are strengthened, however, by the fact that the experiment did not rely on any single mutation or treatment to determine a cell-cycle block, and consistent results were obtained with a variety of mutations and treatments.

\section{Discussion}

The RF-A protein functions during the initiation and elongation stages of DNA replication in vitro and consists of three subunits in both human and yeast cells. Immunofluorescence studies with anti-RF-A monoclonal antibodies have demonstrated that hRF-A is ex- 
clusively a nuclear protein (S. Din and B. Stillman, in prep.). The large subunit (p70 in hRF-A and p69 in yRF-A) binds to single-stranded DNA in the absence of the other subunits and may function like phage and bacterial single-stranded DNA-binding proteins during replication (Brill and Stillman 1989; Kenny et al. 1989; Tsurimoto and Stillman 1989b; Wold et al. 1989). The function of the small subunit is unknown. Results presented herein demonstrate that the p34/p36 subunit of RF-A is phosphorylated in a cell-cycle-dependent manner. A portion of the p34 subunit of hRF-A remains unphosphorylated during the cell cycle, and a portion is also not associated with the p70 subunit /S. Din and B. Stillman, in prep.). Therefore, it appears that only the RF-A complex is phosphorylated, suggesting that phosphorylation affects the function of the protein. Because RF-A is not phosphorylated in the $G_{1}$ phase of the cell cycle but is phosphorylated in the $S$ and $G_{2}$ phases, the p34/p36 subunit may play a regulatory role. Indeed, the studies in yeast suggest that phosphorylation occurs concomitant with DNA replication. Phosphorylation might activate the protein, promote a change in intranuclear locale, or allow association with or dissociation from other proteins, any of which may be required for the onset of DNA replication from each origin of DNA replication in $S$ phase. Alternatively, the phosphorylation of RF-A might occur subsequent to its functioning in DNA replication to prevent over-replication of the genome.

Because RF-A is phosphorylated on serine residues and the protein can be dephosphorylated in vitro by alkaline phosphatase, we have attempted to determine whether dephosphorylated protein is active for DNA replication in vitro. RF-A so treated was added to a replication reaction that contained purified $\mathrm{T}$ antigen, PCNA, RF-C, topoisomerases I and II, and the partially purified fraction IIA (Tsurimoto et al. 1989). Under these conditions, RF-A supported complete DNA replication. In addition, RF-A purified from human cells (Fairman and Stillman 1988) is predominantly in the unphosphorylated form, indicating that it is dephosphorylated during purification yet still supports DNA replication in vitro. But we have recently demonstrated that an RF-A protein kinase exists in fraction IIA and that, under replication conditions, RF-A is rapidly phosphorylated in vitro (A. Dutta and B. Stillman, unpubl.). Therefore, the effect of phosphorylation could not simply be determined without separating the kinase from all of the replication factors present in fraction IIA. Current efforts are directed toward characterizing this protein kinase, including separating it from other replication factors, to reexamine the role of RF-A phosphorylation. Additionally, a genetic approach to this problem is under way in yeast.

The available evidence suggests that positive factors are responsible for activation of DNA replication during the cell cycle (Roberts and D'Urso 1988; Cross et al. 1989). For example, in heterokaryons produced by fusion of cells synchronized in different stages of the cell cycle, $G_{1}$ nuclei can be activated in trans by factors present in
S-phase cells (Rao and Johnson 1970). Therefore, $\mathrm{G}_{1}$ nuclei are competent for DNA replication but must be activated by a positive signal, the nature of which is enigmatic. One possibility supported by the temporal change in RF-A phosphorylation is that at the $G_{1} / S$-phase transition, a cell-cycle-regulated protein kinase phosphorylates RF-A and possibly other replication factors, leading directly to the onset of DNA replication. This scenario is analogous to the role of the maturation promoting factor (MPF), with its cdc2 kinase subunit, in induction of mitosis at a unique point in the cell cycle /Cross et al. 1989; Murray and Kirschner 1989).

Interestingly, recent evidence demonstrated that phosphorylation of SV40 T antigen by the $\mathrm{cdc} 2^{\text {human }} \mathrm{ki}$ nase was required for DNA replication in vitro (McVey et al. 1989). This phosphorylation event may affect the temporal order of virus replication during SV40 infection of quiescent cells by activating $\mathrm{T}$ antigen only when the cells have entered $S$ phase. It seems probable, therefore, that the virus may have pirated a normal cellular mechanism for the regulation of DNA replication. Further characterization of the RF-A kinase and the effects of RF-A phosphorylation may shed light on cell-cycle control of DNA replication and on the nature of the factors that induce the $G_{1}$ - to $S$-phase transition.

\section{Experimental procedures}

Human cells

HeLa and 293 cells were grown in suspension and as described previously (Stillman and Gluzman 1985). Monolayer cultures of these cells were grown in Dulbecco's modified Eagle medium (DMEM) containing $5 \%$ fetal calf serum and $10 \%$ calf serum, respectively. The diploid fibroblast strain WI38 was obtained from the American Type Culture Collection and was grown in DMEM containing $10 \%$ fetal bovine serum.

\section{Yeast strains}

cdc strains were in the A364a genetic background: MATa ura1 ade1 ade2 tyr1 his7 lys2 gal1-1 (Hartwell 1973); and W303-1a is MATa ade2-1 ura3-1 his3-11,15 trp1-1 leu2-3,112 can1-100 (Wallis et al. 1989).

\section{Gel electrophoresis}

SDS-PAGE conditions were described by Laemmli (1970); however, the ratio of acrylamide to bis-acrylamide in the separation gel varied from $29: 1$ to $233: 1$, depending on the percentage of acrylamide.

\section{Cell labeling}

Human cells Approximately $70-80 \%$ confluent cells in 100$\mathrm{mm}$ dishes were labeled with $0.5 \mathrm{mCi}$ of ${ }^{35} \mathrm{~S}$-translabel (ICN) for $16 \mathrm{hr}$ in $3 \mathrm{ml}$ of DMEM containing $3 \mathrm{mg} /$ liter of L-methionine and $10 \%(\mathrm{vol} / \mathrm{vol})$ dialyzed fetal bovine senum (FBS). Alternatively, the same number of human cells were labeled with 1 $\mathrm{mCi}$ [ ${ }^{32} \mathrm{P}$ ] orthophosphate in $3 \mathrm{ml}$ of phosphate-free DMEM containing $10 \%(\mathrm{vol} / \mathrm{vol})$ dialyzed FBS for $16 \mathrm{hr}$.

Yeast cells Yeast strain W303-la was grown overnight at $30^{\circ} \mathrm{C}$ in SD-methionine (Sherman et al. 1986) to a density of $5 \times 10^{7}$ 
cells $/ \mathrm{ml}$. Cells $\left(1 \times 10^{9}\right)$ were pelleted and resuspended in YPD medium without phosphate, containing either $2 \mathrm{mCi}\left[{ }^{32} \mathrm{P}_{\mathrm{PO}_{4}}\right.$ or $1.5 \mathrm{mCi}{ }^{35} \mathrm{~S}$-translabel (ICN). Cells were grown for $2 \mathrm{hr}$ at $30^{\circ} \mathrm{C}$. YPD-phosphate was prepared by precipitating phosphate from 1 liter of YP ( $1 \%$ yeast extract, $2 \%$ Bacto-peptone) with the addition of $10 \mathrm{ml}$ of $1 \mathrm{M} \mathrm{MgSO}_{4}$ and $10 \mathrm{ml}$ of concentrated $\mathrm{NH}_{4} \mathrm{OH}$. The solution was stirred for $30 \mathrm{~min}$ and filtered through Whatman No. 1 paper. The filtrate was made $\mathrm{pH} 6$ with concentrated $\mathrm{HCl}$, autoclaved, and made $2 \%$ glucose.

\section{Immunoprecipitation}

Human cells Cells were washed twice with PBS, scraped with a rubber policeman, when necessary, and collected by centrifugation. For denaturing conditions, cells were lysed with $500 \mu \mathrm{l}$ of $0.1 \%$ (wt/vol) SDS and vortexed, and the lysate was boiled for $5 \mathrm{~min}$. The lysate was adjusted to RIPA buffer [final concentrations, $20 \mathrm{mM}$ Tris (pH 8.0), $0.15 \mathrm{M} \mathrm{NaCl}, 0.5 \%$ deoxycholate, $1 \%$ Triton X-100, and $5 \mathrm{mM} \mathrm{MgCl}_{2}$ ] and precleared by centrifugation in an Eppendorf centrifuge for $5 \mathrm{~min}$ at $4^{\circ} \mathrm{C}$. For native conditions, cells were lysed in $500 \mu \mathrm{l}$ of RIPA buffer and precleared, as described above. Immunoprecipitations were performed by incubation of antibodies (S. Din and B. Stillman, in prep.) with the cell lysate for $2 \mathrm{hr}$ at $4^{\circ} \mathrm{C}$. Then $1 \mu \mathrm{l}$ of rabbit anti-mouse IgG (Dako) (when monoclonal antibodies were used) was added and incubated for $30 \mathrm{~min}$ at $4^{\circ} \mathrm{C}$. The immune complex was precipitated with $50 \mu l$ of bead slurry $[1: 1$ (vol/ vol) protein A-Sepharose/buffer]. After six washes with RIPA buffer, immunoprecipitated proteins were eluted from the protein A-Sepharose beads by boiling in $25 \mu \mathrm{l}$ of sample buffer (Laemmli 1970) for $5 \mathrm{~min}$. Immunoprecipitates were analyzed by electrophoresis in $15 \%$ SDS-polyacrylamide gels, stained with Coomassie Brilliant Blue, treated with $1 \mathrm{M}$ sodium salicylate for $60 \mathrm{~min}$, and dried for autoradiography.

Yeast cells Each sample of cells was washed in deionized $\mathrm{H}_{2} \mathrm{O}$ and split into two $1.5-\mathrm{ml}$ microcentrifuge tubes with $0.2 \mathrm{ml}$ of RIPA buffer and an equal volume of glass beads. Cells were vortexed as vigorously as possible $5 \times 1 \mathrm{~min}$ with alternating 1 -min periods on ice. Samples were diluted up to $1 \mathrm{ml}$ with RIPA buffer, and $0.25 \mathrm{ml}$ of the extract was used for immunoprecipitation. Immunoprecipitations were performed with 2.5 $\mu \mathrm{l}$ of serum for $60 \mathrm{~min}$ on ice. Following a 15 -min preclearing spin, the supernatant was incubated with $60 \mu \mathrm{l}$ of $1: 1$ protein A-Sepharose bead slurry for $20 \mathrm{~min}$ at $4^{\circ} \mathrm{C}$ with rotation. The beads were washed four times with $0.5 \mathrm{ml}$ of RIPA buffer. Beads from ${ }^{32} \mathrm{P}$-labeled samples were treated with $10 \mu \mathrm{l}$ of RNase mix [0.5 M Tris ( $\mathrm{pH} 7.0$ ), $0.05 \mathrm{M} \mathrm{MgCl}_{2}$, and $0.5 \mathrm{mg} / \mathrm{ml} \mathrm{RNase} \mathrm{A]} \mathrm{for}$ $10 \mathrm{~min}$ on ice. The beads were boiled in $50 \mu \mathrm{l}$ of sample buffer, and proteins were subjected to electrophoresis, stained with Coomassie Brilliant Blue, treated with $1 \mathrm{M}$ sodium salicylate for $60 \mathrm{~min}$, and dried for autoradiography.

\section{Immunoblotting}

For immunoblotting experiments, lysate from $2 \times 10^{5}$ human cells was resolved on each lane of a SDS-12\% polyacrylamide gel. Protein was transferred to nitrocellulose in a buffer $25 \mathrm{~mm}$ Tris, $192 \mathrm{~mm}$ glycine, and $40 \%$ (vol/vol) methanol (pH 8.6)] at $\mathrm{l}$ amp for $1 \mathrm{hr}$ at room temperature. Nonspecific protein binding was blocked with $10 \%(\mathrm{vol} / \mathrm{vol})$ FBS and $1 \%$ (wt $/ \mathrm{vol})$ BSA in PBS for $1 \mathrm{hr}$ at room temperature. The filters were probed with the antibodies at $4^{\circ} \mathrm{C}$ overnight, washed for $1 \mathrm{hr}$ with PBS $/ 0.05 \%$ Tween-20, and incubated with rabbit anti-mouse or swine anti-rabbit horseradish peroxidase-conjugated IgG (Dako, $1: 200$ diluted in blocking buffer) for $3 \mathrm{hr}$ at room temperature.
Following washing, the second antibody was detected by incubation of the filter in developing solution containing o-dianisidine (Sigma). The developing solution was prepared as follows: A saturated solution of o-dianisidine was prepared in ethanol. It was diluted $1: 100$ into PBS, and $\mathrm{H}_{2} \mathrm{O}_{2}(30 \%)$ was added (1:5000). The reaction was stopped by washing the filter in water.

\section{Phosphoamino acid analysis}

The $\left[{ }^{32} \mathrm{P}\right]$ orthophosphate-labeled RF-A p34 subunit was immunoprecipitated from a HeLa cell lysate with monoclonal antibody p34-20. After purification by electrophoresis in a SDS-15\% polyacrylamide gel, the p34 was excised from the dried gel by use of the autoradiograph as a template. The protein was extracted from diced slices in $1 \mathrm{ml}$ of $50 \mathrm{mM}$ ammonium bicarbonate $(\mathrm{pH} 7.5), 0.1 \%$ SDS, and $720 \mathrm{~mm} 2$-mercaptoethanol by boiling for $5 \mathrm{~min}$ and agitating at $37^{\circ} \mathrm{C}$ overnight. Phosphoamino acid analysis was performed as described by Cooper et al. (1983).

\section{Yeast cell-cycle analysis}

Method 1 Yeast strain W303-1a was grown to $2.5 \times 10^{7}$ cells/ $\mathrm{ml}$ in YPD at $30^{\circ} \mathrm{C}$. The following manipulations were performed at $30^{\circ} \mathrm{C}$. Cells $\left(2.5 \times 10^{10}\right)$ were loaded into a Beckman JE10X rotor at $1950 \mathrm{rpm}$ and a flow rate of $30 \mathrm{ml} / \mathrm{min}$. Cells were equilibrated with $500 \mathrm{ml}$ YPD, and the pump speed was raised to $60 \mathrm{ml} / \mathrm{min}$. Cells were re-equilibrated at this flow rate with $600 \mathrm{ml}$ of YPD while very small and broken cells were elutriated and discarded. Small cells were elutriated at a flow rate of $70 \mathrm{ml} / \mathrm{min}$ in $600 \mathrm{ml}$ YPD. These cells were then placed in a shaking water bath, and 50-ml samples were taken every 15 min. At each time point, an aliquot of cells was fixed with an equal volume of $3.7 \%$ formaldehyde $/ 0.15 \mathrm{M} \mathrm{NaCl}$. The $50-\mathrm{ml}$ sample was pelleted, washed with $1 \mathrm{ml}$ of deionized $\mathrm{H}_{2} \mathrm{O}$, and frozen as a cell pellet at $-70^{\circ} \mathrm{C}$ in $1.5-\mathrm{ml}$ microcentrifuge tubes. Frozen cells were thawed and lysed by resuspending in $20 \mu \mathrm{l}$ buffer A (Fairman and Stillman 1988) and an equal volume of glass beads. Samples were vortexed as vigorously as possible for $5 \times 1 \mathrm{~min}$ with alternating 1 -min periods on ice. Extracts were subjected to electrophoresis on SDS-17\% polyacrylamide gel and immunoblotted. Immunoblots were probed overnight with anti-p36 antibody and, subsequently, with swine anti-rabbit antibody conjugated to horseradish peroxidase. The fixed cells were microscopically analyzed for the percentage of budded cells. For each time point, a minimum of 100 cells was counted. A small bud is taken to be less than or equal to one-half the size of the mother cell, whereas a large bud is taken to be greater than one-half the size of the mother cell.

Method 2 cdc strains, derived from strain A364a (Hartwell 1973 |, were grown to mid-log phase in YPD at $23^{\circ} \mathrm{C}$ and shifted to $38^{\circ} \mathrm{C}$ for $5 \mathrm{hr}$. Strain W303-la was grown to mid-log phase in YPD at $30^{\circ} \mathrm{C}$ and treated with $\alpha$-factor $(\alpha \mathrm{F})$ at $3 \mu \mathrm{M}$, hydroxyurea at $80 \mathrm{~mm}$ or nocodazole at $20 \mu \mathrm{g} / \mathrm{ml}$ for $3.5 \mathrm{hr}$. Cells were harvested, lysed, and blotted as described above.

Centrifugal elutriation and flow cytometric analysis

These procedures have been described in detail by Draetta and Beach (1988).

\section{Acknowledgments}

We thank Winship Herr, Bruce Futcher, Susan Smith, Tom Me- 
lendy, Toshiki Tsurimoto, and John Diffley for comments on the manuscript, S. Longinotti and N. Kessler for technical assistance, L. Rogers for flow cytometric analysis, and B. Weinkauff for typing the manuscript. This work was supported by grants from the National Institutes of Health (CA-13106 and AI-20460).

\section{References}

Boroweic, J.A. and J. Hurwitz. 1988. Localized melting and structural changes in the SV40 origin of replication induced by $\mathrm{T}$ antigen. EMBO $/ .7: 3149-3158$.

Brill, S.J. and B. Stillman. 1989. Yeast replication factor-A functions in the unwinding of the SV40 origin of DNA replication. Nature 342: 92-95.

Challberg, M.D. and T.J. Kelly. 1989. Animal virus DNA replication. Annu. Rev. Biochem. 58: 671-717.

Cooper, J.A., B.M. Sefton, and T. Hunter. 1983. Detection and quantification of phosphotyrosine in proteins. Methods Enzymol. 99: 387-405.

Cross, F., J. Roberts, and H. Weintraub. 1989. Simple and complex cell cycles. Annu. Rev. Cell Biol. 5: 341-395.

Dean, F.B., P. Bullock, Y. Murakami, C.R. Wobbe, L. Weissback, and J. Hurwitz. 1987. Simian virus 40 (SV40) DNA replication: SV40 large $T$ antigen unwinds DNA containing the SV40 origin of replication. Proc. Natl. Acad. Sci. 84: 16-20.

Draetta, G. and D. Beach. 1988. Activation of $c d c 2$ protein kinase during mitosis in human cells: Cell cycle-dependent phosphorylation and subunit rearrangement. Cell 54: 1726

Fairman, M.P. and B. Stillman. 1988. Cellular factors required for multiple stages of SV40 replication in vitro. EMBO $/$. 7: $1211-1218$

Hartwell, L.H. 1973. Three additional genes required for deoxyribonucleic acid synthesis in Saccharomyces cerevisiae. J. Bacteriol. 115: 966-974.

Kenny, M.K., S.-H. Lee, and J. Hurwitz. 1989. Multiple functions of human single-stranded-DNA binding protein in simian virus 40 DNA replication: Single-strand stabilization and stimulation of DNA polymerases $\alpha$ and $\delta$. Proc. Nat1. Acad. Sci. 86: 9757-9761.

Laemmli, U.K. 1970. Cleavage of structural proteins during the assembly of the head of bacteriophage T4. Nature 227: 680 686.

Laskey, R.A., M.P. Fairman, and J.J. Blow. 1989. S phase of the cell cycle. Science 246: 609-614.

$\mathrm{Li}$, J.J. and T.J. Kelly. 1984. Simian virus 40 DNA replication in vitro. Proc. Natl. Acad. Sci. 81: 6973-6977.

-1985. Simian virus 40 DNA replication in vitro: Specificity of initiation and evidence for bidirectional replication. Mol. Cell. Biol. 5: 1238-1246.

Lowry, O.H., N.J. Rosebrough, A.L. Farr, and R.J. Randall. 1951. Protein measurement with the Folin phenol reagent. J. Biol. Chem. 193: 265-275.

Mastrangelo, I.A., P.V.C. Hough, J.S. Wall, M. Dodson, F.B. Dean, and J. Hurwitz. 1989. ATP-dependent assembly of double hexamers of SV40 T antigen at the viral origin of DNA replication. Nature 338: 652-658.

McVey, D., L. Brizuela, I. Mohr, D.R. Marshak, Y. Gluzman, and D. Beach. 1989. Phosphorylation of large tumour antigen by cdc2 stimulates SV40 DNA replication. Nature 341: 503-507.

Morris, G.F. and M.B. Mathews. 1989. Regulation of proliferating cell nuclear antigen during the cell cycle. $/$. Biol. Chem. 264: 13856-13864.
Murakami, Y., C.R. Wobbe, L. Weissbach, F.B. Dean, and J. Hurwitz. 1986. Role of DNA polymerase $\alpha$ and DNA primase in simian virus 40 DNA replication in vitro. Proc. Natl. Acad. Sci. 83: 2869-2873.

Murray, A.W. and M.W. Kirschner. 1989. Dominoes and clocks: The union of two views of the cell cycle. Science 246: 614621

Pardee, A.B. 1989. $G_{1}$ events and regulation of cell proliferation. Science 246: 603-608.

Patterson, M. R.A. Sclafani, W.L. Fangman, and J. Rosamond. 1986. Molecular of cell cycle gene CDC7 from Saccharomyces cerevisiae. Mol. Cell. Biol. 6: 1590-1598.

Prelich, G., M. Kostura, D.R. Marshak, M.B. Mathews, and B. Stillman. 1987. The cell-cycle regulated proliferating cell nuclear antigen is required for SV40 DNA replication in vitro. Nature 326: 471-475.

Pringle, R. and H. Hartwell. 1981. The Saccharomyces cerevisiae cell cycle. In The molecular biology of the yeast Saccharomyces: Life cycle and inheritance (ed. J.N. Strathern, E.W. Jones, and J.E. Broach), pp. 97-142. Cold Spring Harbor Laboratory Press, Cold Spring Harbor, New York.

Rao, P.N. and R.T. Johnson. 1970. Mammalian cell fusion: Studies on the regulation of DNA synthesis and mitosis. Nature 225: 159-164.

Rao, P.N., P.S. Sunkara, and B.A. Wilson. 1977. Regulation of DNA synthesis: Age-dependent cooperation among $\mathrm{G}_{1}$ cells upon fusion. Proc. Natl. Acad. Sci. 78: 2869-2873.

Reynolds, A.E., R.M. McCarroll, C.S. Newlon, and W.L. Fangman. 1989. Time of replication of ARS elements along yeast chromosome III. Mol. Cell. Biol. 9: 4488-4494.

Roberts, J.M. 1989. Simian virus 40 (SV40) large tumor antigen causes stepwise changes in SV40 origin structure during initiation of DNA replication. Proc. Natl. Acad. Sci. 86: 39393943.

Roberts, J.M. and G. D'Urso. 1988. An origin unwinding activity regulates initiation of DNA replication during mammalian cell cycle. Science 241: 1486-1489.

Sherman, F., G.R. Fink, and J.B. Hicks. 1986. Methods in yeast genetics. Cold Spring Harbor Laboratory Press, Cold Spring Harbor, New York.

Stillman, B. 1989. Initiation of eukaryotic DNA replication in vitro. Annu. Rev. Cell. Biol. 5: 197-245.

Stillman, B.W. and Y. Gluzman. 1985. Replication and supercoiling of simian virus 40 DNA in cell extracts from human cells. Mol. Cell. Biol. 5: 2051-2060.

Tsurimoto, T. and B. Stillman. 1989a. Purification of RF-C, a cellular replication factor required for coordinated synthesis of leading and lagging strands during SV40 DNA replication in vitro. Mol. Cell. Biol. 9: 609-619.

- 1989b. Multiple replication factors augment DNA synthesis by the two eukaryotic DNA polymerases, $\alpha$ and $\delta$. EMBO J. 8: 3883-3889.

Tsurimoto, T., M.P. Fairman, and B. Stillman. 1989. SV40 DNA replication in vitro: Identification of multiple stages of initiation. Mol. Cell. Biol. 9: 3839-3849.

Virshup, D.M. and T.J. Kelly. 1989. Purification of replication factor $C$, a cellular protein involved in the initial stages of simian virus 40 DNA replication in vitro. Proc. Natl. Acad. Sci. 86: 3584-3588.

Virshup, D.M., M.G. Kauffman, and T.J. Kelly. 1989. Activation of SV40 DNA replication in vitro by cellular protein phosphatase 2A. EMBO I. 8: 3891-3898.

Wahl, A.F., A.M. Geis, B.H. Spain, S.W. Wong, D. Korn, and T.S-F. Wang. 1988. Gene expression of human DNA polymerase $\alpha$ during cell proliferation and the cell cycle. Mol. Cell. Biol. 8: 5016-5025. 
Wallis, J.W., G. Chrebet, G. Brodsky, M. Rolfe, and R. Rothstein. 1989. A hyper-recombination mutation in S. cerevisiae identifies a novel eukaryotic topoisomerase. Cell 58: 409-419.

Wobbe, C.R., F. Dean, L. Weissbach, and I. Hurwitz. 1985. In vitro replication of duplex circular DNA containing the simian virus 40 DNA origin site. Proc. Natl. Acad. Sci. 82: $5710-5714$.

Wobbe, C.R., L. Weissbach, J.A. Borowiec, F.B. Dean, Y. Murakami, P. Bullock, and J. Hurwitz. 1987. Replication of simian virus 40 origin-containing DNA in vitro with purified proteins. Proc. Natl. Acad. Sci. 84: 1834-1838.

Wold, M.S. and T. Kelly. 1988. Purification and characterization of replication protein A, a cellular protein required for in vitro replication of simian virus 40 DNA. Proc. Natl. Acad. Sci. 85: 2523-2527.

Wold, M.S., J.J. Li, and T.J. Kelly. 1987. Initiation of simian virus 40 DNA replication in vitro: Large-tumor-antigen and origin-dependent unwinding of the template. Proc. Natl. Acad. Sci. 84: 3643-3647.

Wold, M.S., J.J. Li, D.H. Weinberg, D.M. Virshup, J.L. Sherley, E. Verheyen, and T. Kelly. 1988. Cellular proteins required for SV40 DNA replication in vitro. Cancer Cells 6: 133141.

Wold, M.S., D.H. Weinberg, D.M. Virshup, J.J. Li, and T.J. Kelly. 1989. Identification of cellular proteins required for simian virus 40 DNA replication. J. Biol. Chem. 264: 2801-2809.

Yang, L., M.S. Wold, J.J. Li, T.J. Kelly, and L.F. Liu. 1987. Roles of DNA topoisomerases in simian virus 40 DNA replication in vitro. Proc. Natl. Acad. Sci. 84: 950-954. 


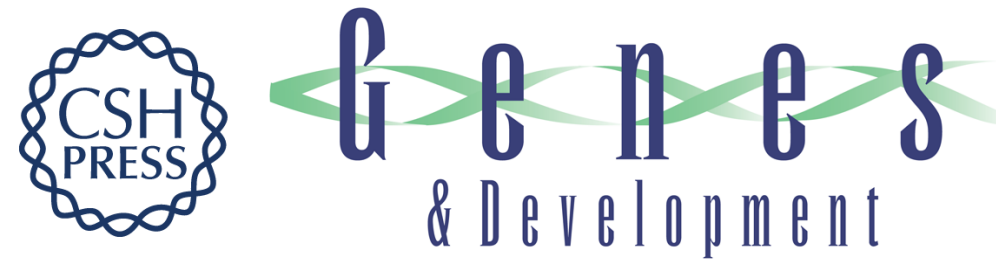

\section{Cell-cycle-regulated phosphorylation of DNA replication factor A from human and yeast cells.}

S Din, S J Brill, M P Fairman, et al.

Genes Dev. 1990, 4:

Access the most recent version at doi:10.1101/gad.4.6.968

References This article cites 44 articles, 26 of which can be accessed free at:

http://genesdev.cshlp.org/content/4/6/968.full.html\#ref-list-1

License

Email Alerting

Service

Receive free email alerts when new articles cite this article - sign up in the box at the top right corner of the article or click here.

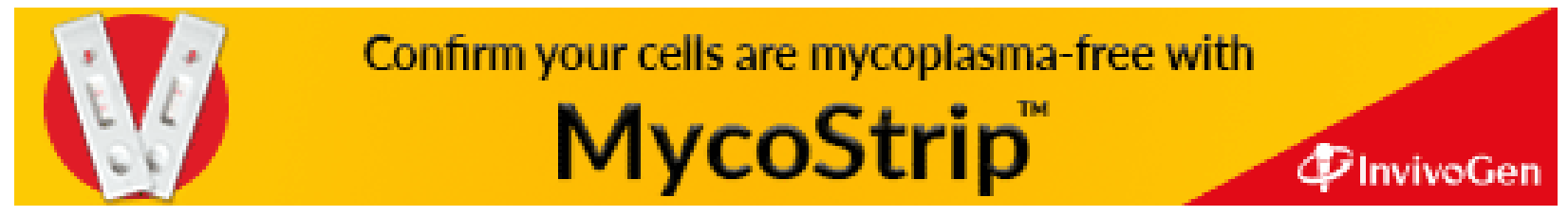

